\title{
太湖微囊藻的生长特征及其 分离纯培养的初步研究
}

\author{
陈宇炜高锡云陈伟民秦伯强
}

(中国科学院南京地理与湖泊研究所, 南京 210008)

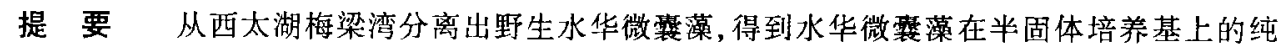

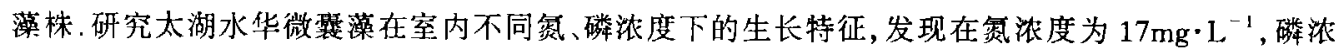
度为 $1.7 \mathrm{mg} \cdot \mathrm{L}^{-1}$ 左右时, 微震藻日增长率最大. 比较自然状态和室内培养条件下微震藻的生长情 况, 可知野生微藻一般能形成较大的群体, 室内液体培养基的营养盐浓度远高于野外, 却难以得 到大群体微露藻, 从此实验结果来看, 营养盐浓度与微露㩰大群体的形成似乎无直接关系. 风浪所 引起的湖底沉积物的再悬浮为水华暴发创造了一定的条件.

关键词太湖 微霊藻 分离 生长特性

分类号 Q949.22

微囊藻 (Microcystis spp.) 是富营养化湖泊中形成“水华” (Water bloom) 的主要藻类.太湖 自八十年代起常出现以微囊藻为优势种的蓝藻水华, 其中主要有铜绿微霅藻 (Microcystis aeruginosa)、大型铜绿微囊藻 ( $M$. aeruginosa var. major)、水华微囊藻( $M$. flos-aquae)、惠氏 微囊藻 $(M$. wesenbergii $)$ 等 ${ }^{[1,2]}$.

近十几年来由于工业迅速发展, 大量工业废水和生活废水排入湖泊等水体, 导致湖泊等水 体的富营养化程度急剧上升. 每到温暖季节, 水华频频暴发, 影响景观, 且水华在气温上升后会 很快腐败,引起水中氧气含量迅速下降, 威胁到水生动物的生存 ${ }^{[3]}$.

国内外对微囊藻在湖泊中的生态结构、功能研究已有几十年历史. Reynolds 在 1975 年研 究了微囊澡群体随光照强度的变化而垂直迁移的现象 ${ }^{[4]}$. Takamura 在 1987 年研究了微霬藻 对碳、氮的吸收情况 ${ }^{[5]}$. Makoto Shirai 等 1989 年成功地用固体培养基分离得到了微囊藻的纯 藻株 ${ }^{[6]}$. Caiola Marla Grill 等在 1991 年研究了微囊藻上附生的一种芽胞杆菌, 发现水华暴发与 该菌的生长情况有一定关系 ${ }^{[7]}$. 国内微囊藻研究初期主要集中在种类鉴定和毒理分析方面. 李 仁辉等进行了绿色微囊藻的种类鉴定 ${ }^{[8]}$. 何家苑等研究了铜绿微囊藻、惠氏微囊藻的毒

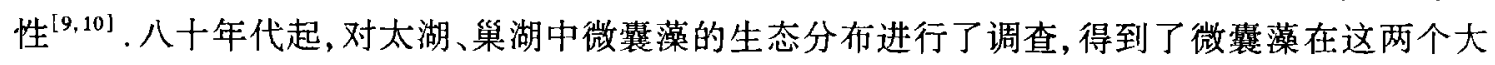
型浅水湖泊中分布的大致轮廕 ${ }^{[11,12]}$ 。“巢湖富营养化研究”课题组对微囊藻生长的限制因子及 划浓度的研究, 使得国内对微囊藻个体生态学的研究进一步深入 ${ }^{[12]}$. 本研究就是在此基础上, 初步了解太湖的微囊藻室内培养的生长特性并试图用固体培养基分离纯藻种, 为深入研究太 湖蓝藻水华暴发机理及其与细菌等的生态关系提供帮助.

* 国家自然科学基金(39500027,39600025)、中国科学院重大项目 (KZ951-B1-205-02)、(KZ951-A1-301)、中国科 学院重点项目 (KZ9512-S1 - 220)和中国科学院“九五”特别支持顶目 (KZ95T - 04-04)联合资助. 收稿日期: 1998-06-11;收到修改稿日期: 1998-10-05. 陈宇炜, 男, 1969 年生, 助理研究员. 


\section{1 材料与方法}

\section{1 藻种来源}

用 25 号浮游生物网 (孔径 $63 \mu \mathrm{m}$ ) 在西太湖梅梁湾捞取野生微囊藻, 置于烧杯中静置, 取上 浮部分用蒸馏水清洗后再静置, 取上浮部分清洗, 如此重复三次, 用 $120 \mu \mathrm{m}$ 滤网过滤去除较大 群体, $30 \mu \mathrm{m}$ 滤网去除较小群体和单细胞, 将群体大小介于 $120-30 \mu \mathrm{m}$ 之间的微囊藻在显镜 下挑取群体完整的水华微囊藻作室内培养的原始薬种.

\section{2 液体培养}

上述原始藻种用 Allen BG-11 培养基进行液体培养, 配方如下:

$\begin{array}{llll}\mathrm{NaNO}_{3} & 1.5 \mathrm{~g} \cdot \mathrm{L}^{-1} & \mathrm{H}_{3} \mathrm{BO}_{3} & 0.00286 \mathrm{~g} \cdot \mathrm{L}^{-1} \\ \mathrm{~K}_{2} \mathrm{HPO}_{4} & 0.04 \mathrm{~g} \cdot \mathrm{L}^{-1} & \mathrm{MnCl}_{2} \cdot 4 \mathrm{H}_{2} \mathrm{O} & 0.00181 \mathrm{~g} \cdot \mathrm{L}^{-1} \\ \mathrm{MgSO}_{4} & 0.075 \mathrm{~g} \cdot \mathrm{L}^{-1} & \mathrm{ZnSO}_{4} \cdot 7 \mathrm{H}_{2} \mathrm{O} & 0.000222 \mathrm{~g} \cdot \mathrm{L}^{-1} \\ \mathrm{CaCl}_{2} 2 \mathrm{H}_{2} \mathrm{O} & 0.036 \mathrm{~g} \cdot \mathrm{L}^{-1} & \mathrm{Na}_{2} \mathrm{MoO}_{4} \cdot 2 \mathrm{H}_{2} \mathrm{O} & 0.00039 \mathrm{~g} \cdot \mathrm{L}^{-1} \\ \text { 柠檬酸 } & 0.006 \mathrm{~g} \cdot \mathrm{L}^{-1} & \mathrm{CuSO}_{4} \cdot 5 \mathrm{H}_{2} \mathrm{O} & 0.000079 \mathrm{~g} \cdot \mathrm{L}^{-1} \\ \text { 柠檬酸铁 } & 0.006 \mathrm{~g} \cdot \mathrm{L}^{-1} & \mathrm{Co}\left(\mathrm{NO}_{3}\right)_{2} \cdot 6 \mathrm{H}_{2} \mathrm{O} & 0.0000494 \mathrm{~g} \cdot \mathrm{L}^{-1} \\ \mathrm{Na}_{2} \text {-EDTA } & 0.001 \mathrm{~g} \cdot \mathrm{L}^{-1} & \mathrm{pH} & 7.1 \\ \mathrm{Na}_{2} \mathrm{CO}_{3} & 0.02 \mathrm{~g} \cdot \mathrm{L}^{-1} & & \end{array}$

1.2 .1 水华微囊藻的生长曲线 培养条件: 原始藻种接入 $500 \mathrm{~mL}$ 三角瓶, 内装 $300 \mathrm{~mL}$ 培养 基, 温度 $30 \pm 1^{\circ} \mathrm{C}$, 光强 $500 \mu \mathrm{E} \cdot \mathrm{m}^{-2} \mathrm{~s}^{-1}$, 光暗比 $12 \mathrm{~h}: 12 \mathrm{~h}$. 培养方法: 磁力摚拌和静置加定时摇 晃两种连续培养方式.

\section{2 .2 氮、磷浓度对微囊藻生长的影响}

（1）培养基: 以 BG-11 培养基为基础, 根据单因子培养法按下列氮、磷浓度配制.

组别

氮 $/ \mathrm{mg} \cdot \mathrm{I}^{-1}$

磷/ $\mathrm{mg} \cdot \mathrm{L}^{-1}$

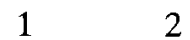

6.8

0.02

7.8

1.69
3

13.2
4

13.4

7.15
5

27.3

10.8
$6 \quad 7$

$55.8 \quad 230$

$15.5 \quad 22.6$

(2) 培养条件: 等量原始藻种加入各培养三角瓶中, 每瓶 $300 \mathrm{~mL}$ 培养基, 温度 $26 \pm 2{ }^{\circ} \mathrm{C}$, 光 强 $\mu \mathrm{E} \cdot \mathrm{m}^{-2} \cdot \mathrm{s}^{-1}$, 光暗比 $12 \mathrm{~h}: 12 \mathrm{~h}$.

\section{3 固体培养}

含 $0.5 \%$ 琼脂的 BG-11 培养基平板倾皿法分离原始藻种. 含 $0.9 \%$ 琼脂的 BG-11 培养基 涂布法及划线法进一步纯化. 光照培养箱条件: 光强 $500 \mu \mathrm{E} \cdot \mathrm{m}^{-2} \mathrm{~s}^{-1}$, 温度 $29 \pm 2^{\circ} \mathrm{C}$.

\section{4 生物量测定}

叶绿素 $\mathrm{a}$ 含量用单色分光光度法测定, Lorenzen 公式计算. 藻类细胞数采用 $0.1 \mathrm{~mL}$ 浮游 生物计数框, 以显微镜视野法计数, 并由细胞数换算成生物量.

\section{5 藻类日增长率计算}

在连续液体培养时, 每天定时采样, 测定叶绿素 a 含量和细胞数, 依下式计算日增长率

$$
U=\left(N_{t}-N_{t-1}\right) / N_{t-1}
$$

式中, $U$ 为日增长率; $N_{t}$ 为当天生物量; $N_{t-1}$ 为前一天生物量. 


\section{6 微震藻自然生长状况}

从 1991 年 10 月至 1997 年 12 月, 每月一次在太湖梅梁湾定点采样, 得到微囊藻生物量的 周年变化情况, 同时测定光照、温度、 $\mathrm{pH}$ 、透明度、风浪等物理因子和氮、磷等化学因子.

\section{2 结果与讨论}

\section{1 太湖的水华微標藻的生长曲线和固体培养}

在原始藻种适应 BG-11 液体培养基后, 运用平板倾血法在 $0.5 \%$ 琼脂培养基上长成的微 囊藻群体呈条带状, 再经划线分离在 $0.9 \%$ 的琼脂培养基上得到的微囊藻单藻落为绿色半球 状, 表面光滑, 直径 $1.5 \mathrm{~mm}$ 左右. 挑取单藻落再次划线分离仍然得到同样的单藻落, 说明已分 离出水华微囊藻的纯藻株. Makoto Shiral 所分离的微囊藻主要是铜绿微露藻和惠氏微囊藻, 但没有说明如何在固体培养基上区分两种微囊藻单藻落 ${ }^{[6]}$. 本研究由于在原始藻种的选择上

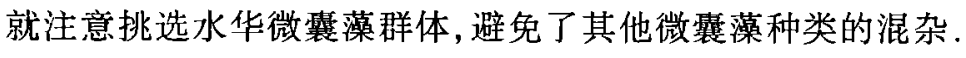

图 1 为水华微囊藻在室内液体培养的 生长曲线.第一、二天微衰藻生物量变化较 小, 是处于生长延迟期, 镜检可见群体完整 而只有少量单细胞; 第三天起, 生物量以较 快的速度增长, 显微镜下可见其中相当多 的藻细胞两两一起, 明显是正在进行细胞 分裂, 并有十个左右细胞组成的小群体, 说 明已到了对数生长期; 到第六天, 藻类生物 量达到最大值, 但培养基中只有单细胞和 小群体, 未见水华状群体; 第七、八天起生 物量开始稳定和下降, 微囊澡生长进入稳

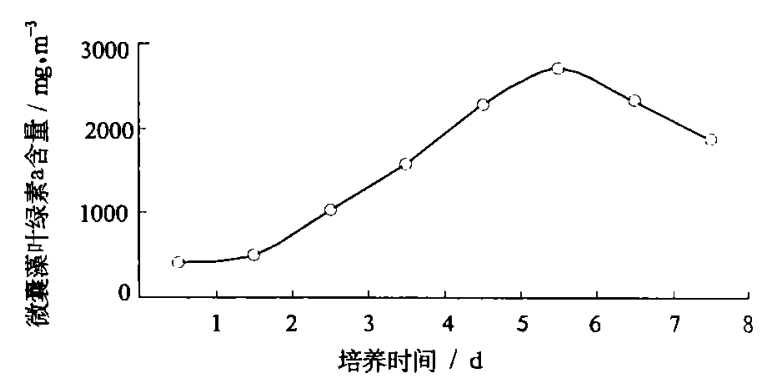

图 1 太湖的水华微震藻室内培养的生长曲线

Fig. 1 The indoor culture growth curve of Micocystis flos-aquae from Taihu Lake

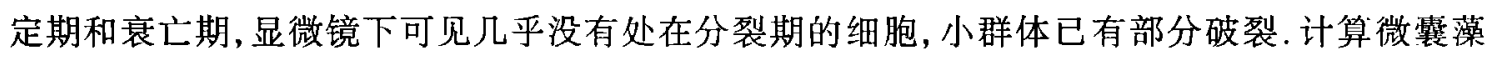
的日增长率, 得最大值为 0.9 , 说明在室内培养条件下微震藻生物量能够每天增长近一倍, 这 一结果符合太湖夏季微囊藻水华在几天内暴发的现象.

\section{2 氮、磷浓度对太湖微㕝藻生长的影响}

氮、磷是藻类生长所需的重要营养盐, 也是许多湖沼学家关注的重要环境因子之一. 图 2 反映了不同氮、磷浓度对微囊澡日增长率的影响情况, 可以看出, 当总溶解性氮 (TDN) 浓度在 $17 \mathrm{mg} \cdot \mathrm{L}^{-1}$ 左右、磷酸根 $\left(\mathrm{PO}_{4}^{3-}\right)$ 浓度在 $1.7 \mathrm{mg} \cdot \mathrm{L}^{-1}$ 左右时, 微囊藻的日增长率最大, 说明此浓 度可能是太湖微賈藻生长的最佳条件. 低于此浓度微囊藻日增长率随氮、磷浓度增加而加大, 高于此浓度微囊藻日增长率随氮、磷浓度增加而减小. 因此并非营养盐浓度越高微霊藻生长就 越快. Bucka 在总结几种能引起水华的浮游藻类的生态特征时提到,微囊藻水华暴发与氮、磷 等营养盐浓度并无直接关系 ${ }^{[13]}$. Christian 也提到每种能引起水华的藻类都有其特定的合适营

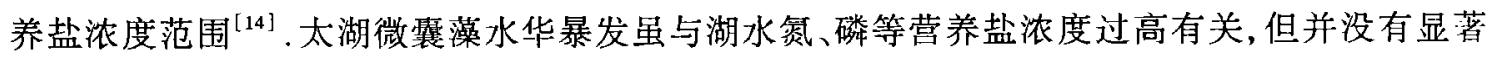
的相关关系 ${ }^{[15]}$.

\section{3 太湖微賈藻在自然状态下和室内培养下的差异}

图 3 是近几年太湖梅梁湾中部微霊澡生物量年变化动态, 可以看出, 各年微囊澡暴发规模 

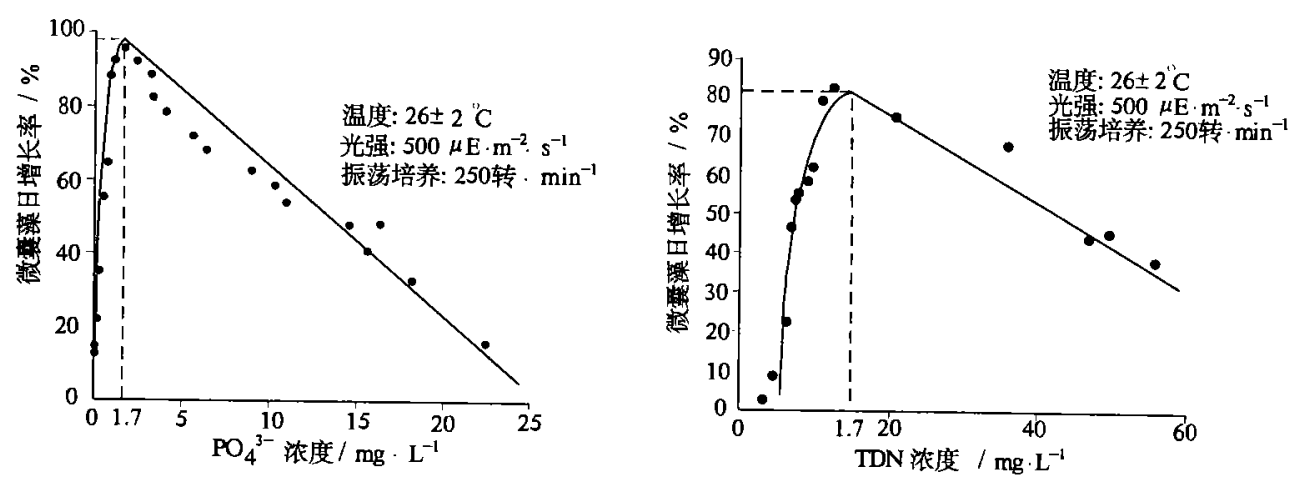

图 2 太湖微霜藻日增长率与 $\mathrm{PO}_{4}^{3-}$ 浓度及与 $\mathrm{TDN}$ 浓度的关系

Fig. 2 The relation between $\mathrm{PO}_{4}^{3-}$, TDN concentration and Microcystis growth rate of Taihu Lake

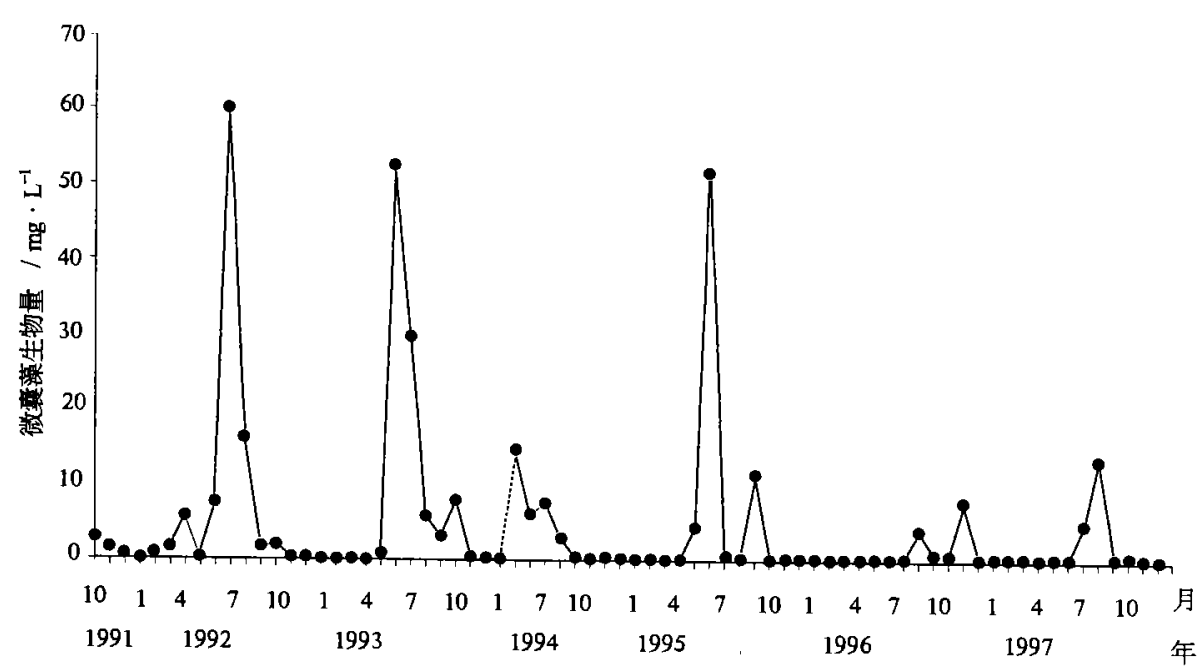

图 3 太湖梅梁湾中部微震藻生物量动态

Fig. 3 The dynamics of Microcystis biomass in the middle of Meiliang Bay, Taihu Lake

不尽相同,生物量分布一年中变化很大, 但暴发时间都在 6-8 月之间. 近几年监测结果显示, 梅梁湾营养盐浓度四季变化幅度较小, 甚至在微穰藻水华暴发的 6-8 月份可溶性氮、磷营养 盐浓度有时还略低于其他时期, 说明太湖微褧藻在水华暴发前有一个缓慢生长与营养盐富集 过程. 另外通过野外标本观测可见太湖微襄藻在各年 2,3 月份就可见小群体, 到 4,5 月份起有 大群体出现,在夏季多数为群体直径在 $30 \mu \mathrm{m}$ 以上, 细胞数超过 100 个的大群体形成水华, 说 明微亭澡在自然状态下主要以群体形态存在; 而室内培养的微囊藻最多形成十几个细胞的小 群体. 究其原因可能由于太湖水体浊度大, 透明度低, 光照条件变化大, 据现场实测资料, 梅梁 湾地区阴天天气时表层水下光强一般是 $200 \mu \mathrm{E} \cdot \mathrm{m}^{-2} \cdot \mathrm{s}^{-1}$, 少云天气光强可达 $1500-2000 \mu \mathrm{E}$. 
$\mathrm{m}^{-2} \cdot \mathrm{s}^{-1}$, 大群体微囊藻有气震, 可根据不同的光照条件悬浮于合适的水层, 以得到最佳生长 环境; 而室内培养的光强最大是 $500 \mu \mathrm{E} \cdot \mathrm{m}^{-2} \cdot \mathrm{s}^{-1}$, 且光照均匀, 单细胞和小群体可减少相互之 间的光遮蔽, 使得微囊藻单细胞生长可利用更多的光能, 而且室内培养采用振荡或通气条件, 也使微囊藻单细胞难以形成大群体. Christian 也认为浊度变化所引起的光照水下不同分布对 蓝藻垂直运动和形成大群体有作用 ${ }^{[14]}$. 另外室内培养基营养盐浓度而且较稳定, 单细胞或小 群体有利于微囊藻随时吸收营养; 而自然湖水营养盐浓度相对较低, 大群体微襄藻可在周围湖 水营养盐较丰富时吸收并财存营养盐, 待周围营养盐贫乏时用于生长. 野外实测资料还显示, 水华暴发与风力傥动过程相符 ${ }^{[16]}$. 风浪所引起的湖底沉积物的再悬浮为水华暴发创造了一定 的条件.

总之, 太湖微亚藻水华暴发并非由过高的氮磷营养盐浓度这一单因子引起的, 风浪及其引 起的湖水浑浊度的变化所带来的影响有待进一步的研究.

致谢本研究在实验过程中得到欧辉和胡伟的大力帮助, 季江高工参加了大部分野外 采样工作, 中国科学院太湖湖泊生态系统研究站提供了部分野外资料,在此一并致谢.

\section{参 考 文 献}

1 朱浩然.中国淡水藻志——色球藻纲. 北京:科学出版社, 1991

2 陈宇炜, 高锡云. 西太湖北部微醌藻时空分布及其光照等环境因子关系的研究. 见: 蔡启铭编, 太湖环境生态研究 (一), 北 京:气象出版社, 1998

3 前家禄等.武汉东湖蓝藻水华毒性研究 (I) : 淡水蓝藻水华毒性的检测.水生生物学报, 1987, 11(3):212-217

4 Reynolds C S \& Walsby A E. Water blooms. Biological Reviews, 1975, 50:437-481

5 Takamura N, Iwakuma T \& Yasuno M. Uptake of ${ }^{13} \mathrm{C}$ and ${ }^{14} \mathrm{~N}$ (ammonium, nitrate and urea) by Microcystis in Lake Kasumigaura. J Plankton Res, 1987, 9:151-165

6 Makoto Shirai, et al. Development of a soild medium for growth and isolation of axenic Microcystis strains (Cyanobacteria). App Enviro Microbiology, 1989, 10:2569-2571

7 Maria Grilli Caiola. Bdellovibrio-like bacteria in Microcystis aeruginosa. Algalogical Studies, 1991, 64:369-376

8 李仁辉等. 中国新记录蓝藻一绿色微辕藻及其毒性的初步研究.水生生物学报, 1993, 17(3):282-284

9 何家塚等. 东湖铜绿微賈藻的分离与鉴定. 海洋与湖沼, 1988, 19(5):424-430

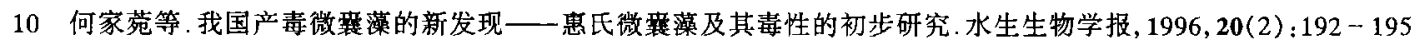

11 屠清瑛等.巣湖——富营养化研究.合肥:中国科学技术大学出版社, 1990.82-100

12 孙顺才, 黄渏平.太湖. 北京: 海洋出版社, 1993.159-170

13 Bucka H. Ecology of Selected planktonic algal causing water blooms. Acta Hydrobiol, 1989, 31(3/4):207-258

14 Christian E W, et al. Planktonic bloom-forming Cyanobacteria and the eutrophication of lakes and rivers. Freshwater Biology, 1988, 20:279-287

15 高锡云等. 梅梁湾及大太湖水环境现状特征与富营养化趋势分析.见:蔡启铭编.太湖环境生态研究 (一), 北京:气象出 版社, 1998

16 Reynolds C S. The ecology of the planktonic blue-green algae in the north Shropshire meres. Fld Stud, 1971, 3:409-432 


\title{
Growth Characters and Pure Culture of Microcystis from Taihu Lake
}

\author{
CHEN Yuwei GAO Xiyun CHEN Weimin QIN Boqiang \\ (Nanjing Institute of Geography $\hat{\oplus}$ Limnology, Chinese Academy of Sciences, Nanjing 210008)
}

\begin{abstract}
This study deals with the growth characters and pure culture of Microcystis from Taihu Lake. It is found that Microcystis flos-aquae can grow in solid medium. The results also show that both phosphorus and nitrogen play an important role during the growth period of Microcystis flos-aquae. The maximum growth rates appear when the $\mathrm{PO}_{4}^{3-}$ concentration reach $1.7 \mathrm{mg} \cdot \mathrm{L}^{-1}$ and the TDN concentration reached $17 \mathrm{mg} \cdot \mathrm{L}^{-1}$. Comparing the indoor culture of Microcystis with the Microcystis in the lake, there is a clear difference in their growth characters. The Microcystis in the lake normally appears as big colony while it appears only single cell or small colony with ten cells in indoor culture.
\end{abstract}

Key Words Taihu Lake, Microcystis, pure culture, growth character 